\title{
Anatomy of Open Access Mathematics Journals
}

Prabir Kumar Das*

\author{
Library, Documentation and Information Science Division, Indian Statistical Institute, 203 B.T. Road, \\ Kolkata - 700108, India; prabirdas2003@yahoo.com
}

\begin{abstract}
Present study focuses on analysis of open access journals in the field of mathematics based on data collected from DOAJ. It highlights various facets of open access publishing like growth, publishing country, language, publisher, funding model and licensing. Open access journals in mathematics are published in 22 languages from 64 countries by 394 publishers across the globe. It was seen that mathematics OA journals started appearing in DOAJ during 2002; afterwards there has been incessant flow of new titles; 96 new titles were added in 2011. Interestingly developing countries like India, Egypt, and Brazil have embraced OA. English is the most preferred language, Professional's organisations, commercial publishers are involved in OA mathematics publishing, of which Hindawi Publishing Corporation (9\%) is the leading contributor. The study also reaffirms pervasive nature of mathematics owing to the existence of large array of multi-disciplinary $\mathrm{OA}$ journals. It is seen that majority of OA journals do not charge APC.
\end{abstract}

Keywords: Bibliometrics, Directory of Open Access Journals, DOAJ, Mathematics, OA Journals, Open Access

\section{Introduction}

In the present knowledge economy, universal access to relevant information and knowledge is indispensable. Subscription-based access to scholarly information (predominantly print journals) not only poses significant hurdles (pricing and legal restrictions) to free dissemination but also restricts the potential impact of 'research output'. The emergence of Open Access (OA) has challenged the prevailing publishing model. Triggered by information and communication technology (especially Internet), OA has revolutionized scholarly publishing. The mechanism that primarily emerged as 'an alternative publishing model' to manage the 'serial crisis', eventually transformed the scholarly publishing landscape ${ }^{1}$. Different stakeholders of scholarly communication systems (viz. researchers, affiliated institutions, funding agencies, publisher and society) can and will benefit substantially from $\mathrm{OA}^{2}$. Despite, faster publication and easier access, OA publication brings increased visibility and usage which leads to greater impact ${ }^{3}$ and citation ${ }^{4}$. Thus, Open Access provides far-reaching benefits to users and responds to the limitations of traditional subscriptionbased publishing system ${ }^{5}$.

\subsection{Open Access Journals: Philosophy and Facility}

In the context of scholarly publishing, Open Access refers to unrestricted free access to digital information. According to Suber ${ }^{6}$, OA removes price barriers (subscriptions, licensing fees, pay-per-view fees) and permission barriers (copyright and licensing restrictions) thereby making resources available with minimal restrictions. The essential premise of OA publishing is that society in general benefits from open exchange of ideas and innovations unencumbered from the limitations of subscription costs, licensing fees and copyright restrictions of subscription-based publishing models ${ }^{7}$. Ever since OA publishing came into practice as an alternative mode for dissemination of scholarly information, there has been a plethora of OA journals in all branches of knowledge. Mathematics influences the entire gamut of science and scientific research ${ }^{8}$. Mathematics as a discipline is very mush distinguished for its universality. It has been aptly called as language of science ${ }^{9}$; queen of science ${ }^{10}$ and whetstone of intelligence ${ }^{11}$. Evidently, mathematics advances through the creation of new concepts and methods. 


\section{Review of Literature}

Open Access movement has gained support across the globe with a number of initiatives to promote and facilitate OA. Numerous papers have been published to interpret viewpoints, demonstrate methodological approaches and potential benefits of OA publishing. Here we highlight some subject-specific studies focusing on features of OA literature in major disciplines of humanities ${ }^{12-14}$; natural science $^{15-22}$; social sciences ${ }^{23-25}$; besides a few studies in the field of library and information sciences ${ }^{26-32}$ and technology ${ }^{33-34}$. This review is not exhaustive.

\section{Scope and Objectives}

The present study is limited to mathematics OA journals retrieved from DOAJ. In spite of some criticism ${ }^{35} \mathrm{DOAJ}$ is preferred because of its comprehensiveness and flexible policy towards accessibility and discoverability ${ }^{36}$. OA journals that are not registered in DOAJ and other titles in other disciplines covered in DOAJ but do not explicitly focus on Mathematics are not included in this study. The specific objectives of the study are as follows:

- To examine the growth of OA journals in mathematics;

- To identify the leading publishers of mathematics OA journals;
- To map distribution of OA journals in different branches of mathematics;

- To show geographical distribution of mathematics OA journals; and

- To determine language-wise distribution of $\mathrm{OA}$ journals.

\section{Data Collection and Methodology}

Keeping in view the aforesaid objectives, a search for: "Journal" and "subject" = 'mathematics' in the DOAJ database, was made which yielded 601 hits on 31/12/2014 (Figure 1). Noteworthy is the fact that, the 'subject' data field of $D O A J$ invariably contains more than one 'subject'. Bibliographic attributes of retrieved journals like - title, ISSN, Publisher, country of origin, language, starting date, APC, licensing type, URLs, etc. were collected and transcribed to MS Excel spread sheet. Retrieved URL of individual journals was confirmed by searching the title as phrase query in leading search engines like Google and Yahoo. Access policy (free/ partially free / subscriptionbased), authoritativeness and functionalities of particular e-journals were further ascertained by visiting the URL of retrieved journals. Relevant bibliometric techniques were applied to analyze the retrieved dataset objectively.

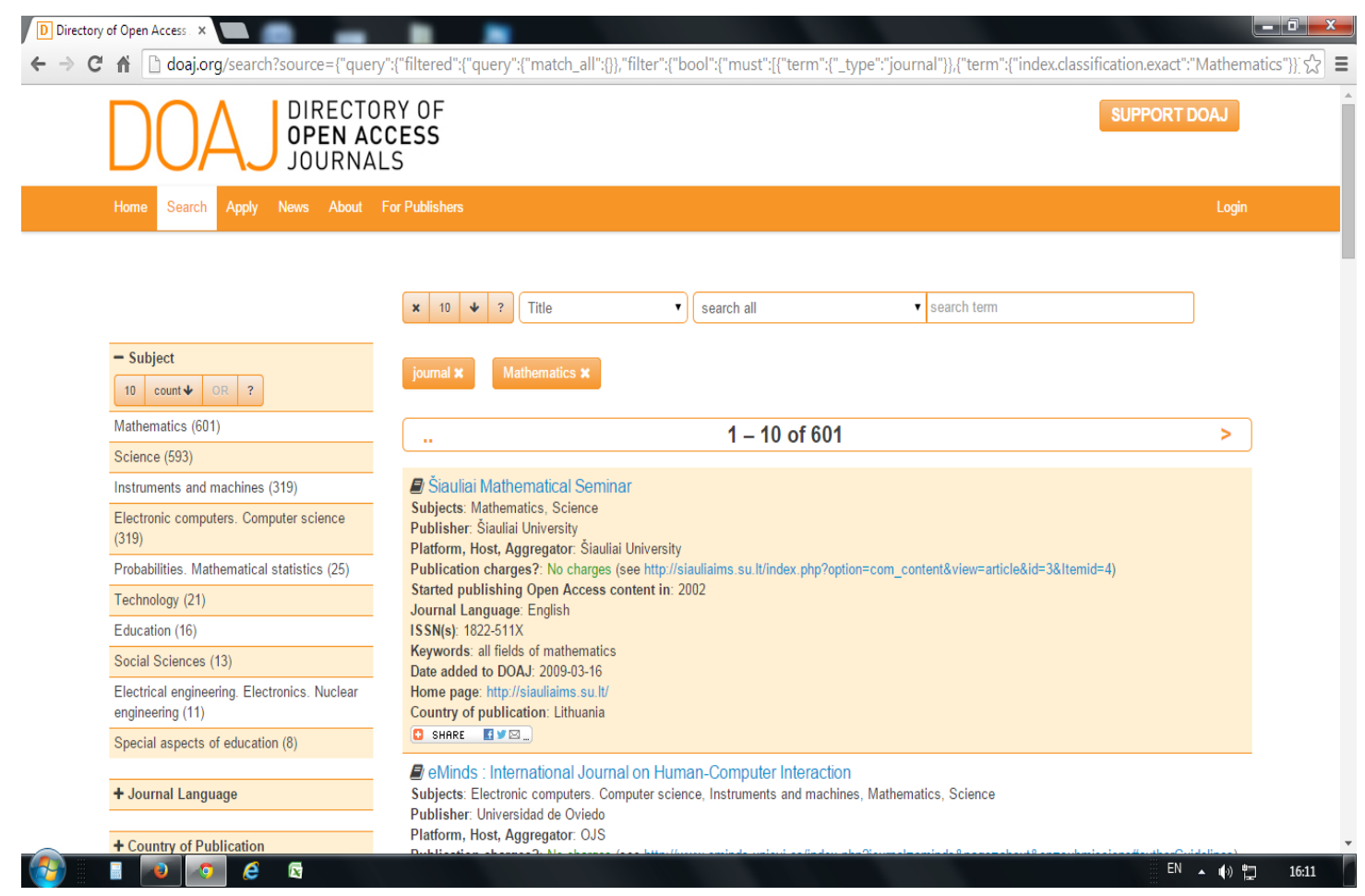

Figure 1. Search result of DOAJ (as on 31/12/2014). 


\section{Analysis and Findings}

To assess the growth and impact of open access mathematics journals, different bibliometric parameters of journals have been analysed.

\subsection{Year-wise Growth of OA Mathematics Journals}

Table 1 shows chronological growth of OA journals in mathematics. There were only $4 \mathrm{OA}$ journals in mathematics up to 1980 , another 4 new journals appeared in the next decade, another 81 appeared during 1990s. But 21st century has witnessed tremendous proliferation of 308 (51.24\%) of mathematics OA journals followed by moderate growth 204 (45\%) during 2010s. It is evident that during the last two decades there has been a steady growth of mathematics OA journals. It is also significant, that though maximum growth was recorded during 2000s, the year 2011 shows maximum growth (96) in terms of new journals. Mathematics OA journals started appearing in DOAJ during 2002, when more than $100 \mathrm{OA}$ mathematics journals already existed.

\subsection{Country-wise Distribution of OA Journals in Mathematics}

Table 2 represents the distribution of OA mathematics journals by country of origin. 64 countries across the world have contributed to publish 601 mathematics OA journals. The top six countries have produced more than

Table 1. Growth of Mathematics OA journals

\begin{tabular}{|c|c|c|c|c|c|c|}
\hline Decade & Year of Origin & Frequency (Year-wise) & Frequency (Decade-wise) & $\%$ & Date of DOAJ appearance & $\%$ \\
\hline Up to 1980 & 1978 & 4 & 4 & 0.67 & & \\
\hline \multirow{2}{*}{ Up to 1990} & 1981 & 2 & 4 & 0.67 & & \\
\hline & 1990 & 2 & & & & \\
\hline \multirow[t]{10}{*}{ 1990s } & 1991 & 2 & 81 & 13.48 & & \\
\hline & 1992 & 2 & & & & \\
\hline & 1993 & 7 & & & & \\
\hline & 1994 & 6 & & & & \\
\hline & 1995 & 4 & & & & \\
\hline & 1996 & 9 & & & & \\
\hline & 1997 & 11 & & & & \\
\hline & 1998 & 11 & & & & \\
\hline & 1999 & 11 & & & & \\
\hline & 2000 & 18 & & & & \\
\hline \multirow[t]{10}{*}{2000 s } & 2001 & 13 & 308 & 51.24 & & \\
\hline & 2002 & 15 & & & 3 & 0.50 \\
\hline & 2003 & 13 & & & 36 & 5.99 \\
\hline & 2004 & 19 & & & 17 & 2.83 \\
\hline & 2005 & 23 & & & 29 & 4.83 \\
\hline & 2006 & 35 & & & 23 & 3.83 \\
\hline & 2007 & 29 & & & 25 & 4.16 \\
\hline & 2008 & 36 & & & 32 & 5.32 \\
\hline & 2009 & 62 & & & 38 & 6.32 \\
\hline & 2010 & 63 & & & 90 & 14.98 \\
\hline \multirow[t]{4}{*}{2010 s } & 2011 & 96 & 204 & 33.97 & 92 & 15.31 \\
\hline & 2012 & 65 & & & 70 & 11.65 \\
\hline & 2013 & 39 & & & 138 & 22.96 \\
\hline & 2014 & 4 & & & 8 & 1.33 \\
\hline Total & & 601 & 601 & 100.00 & 601 & 100.00 \\
\hline
\end{tabular}


Table 2. Country-wise distribution of OA Mathematics journals

\begin{tabular}{llccc}
\hline Rank & Country of Origin & No of Jls & \% & Cum. \% \\
\hline 1 & India & 83 & 13.81 & 13.81 \\
2 & USA & 82 & 13.64 & 27.45 \\
3 & Egypt & 58 & 9.65 & 37.10 \\
4 & Germany & 32 & 5.32 & 42.43 \\
5 & Romania & 30 & 4.99 & 47.42 \\
6 & Spain & 17 & 2.83 & 50.25 \\
7 & Brazil & 14 & 2.33 & 52.58 \\
8 & Canada, Hong Kong \& Iran & 13 each & 2.16 X 3 & 59.07 \\
9 & Japan & 12 & 2.00 & 61.06 \\
10 & Indonesia, Malaysia, Serbia, S. Korea & 11 each & 1.83 X4 & 68.38 \\
11 & France, Italy, UK & 10 each & 1.66 X3 & 73.38 \\
12 & Bulgaria, Pakistan, Poland, Singapore, Switzerland, Turkey & 9 & $1.50 X 6$ & 82.36 \\
13 & Austria, Colombia, Ukraine & 6 each & $1.00 X 3$ & 85.36 \\
14 & Australia, Finland, Russian Federation, Slovakia & 5 each & $0.83 X 4$ & 88.69 \\
15 & Chile, Jordan, Mexico, New Zealand, Taiwan & 4 each & $0.67 X 5$ & 92.01 \\
16 & Croatia, Czech Republic, Hungary, Kosovo, Netherlands, Portugal & 3 each & $0.50 X 6$ & 95.01 \\
17 & Argentina, Cuba, Georgia, Lithuania, Moldova, Slovenia, UAE \& Venezuela & 2 each & $0.33 X 8$ & 97.67 \\
18 & Another 14 Countries & 1 each & $0.17 X 14$ & 100.00 \\
\hline & Total 64 Countries & $\mathbf{6 0 1}$ & $\mathbf{1 0 0 . 0 0}$ & $\mathbf{1 0 0 . 0 0}$ \\
\hline
\end{tabular}

half $(50.25 \%)$ of the total OA journals in mathematics. Significantly, India being a developing nation is the most productive country (marginally overtook USA) in terms of number of OA journals in mathematics. Notably countries like China, UK (11th), France (11th) and Switzerland (12th) are not found among the top countries. Therefore, prevalence of developing countries (India, Egypt and Brazil) is observed in this study which might be a good sign for global OA movement. The observation seems to comply with other studies ${ }^{37}$ about country-wise production of OA journals.

\subsection{Language of OA Mathematics Journals}

Table 3 provides information about the language of $\mathrm{OA}$ journals in Mathematics. OA journals in mathematics

Table 3. Language-wise distribution of OA Mathematics journals

\begin{tabular}{|l|c|}
\hline Language-wise distribution of OA Mathematics Journals \\
\hline Mono-Lingual Journals & Frequency \\
\hline English & 509 \\
\hline Spanish & 6 \\
\hline Chinese & 5 \\
\hline French & 2 \\
\hline Portuguese & 2 \\
\hline Russian & 2 \\
\hline German & 1 \\
\hline Croatian & 1 \\
\hline & Total = 528 (87. 85\%) \\
\hline Bi-Lingual Journals & Frequency \\
\hline English, French & 13 \\
\hline
\end{tabular}

\begin{tabular}{|c|c|}
\hline English, Spanish & 11 \\
\hline English, German & 4 \\
\hline English, Portuguese & 4 \\
\hline English, Indonesia & 3 \\
\hline English, Italian & 3 \\
\hline English, Japanese & 3 \\
\hline English, Russian & 3 \\
\hline English, Arabic & 1 \\
\hline English, Indonesia & 1 \\
\hline English, Chinese & 1 \\
\hline English, Malay & 1 \\
\hline English, Polish & 1 \\
\hline English, Romanian & 1 \\
\hline \multirow[t]{2}{*}{ English, Turkish } & 1 \\
\hline & Total $=51(8.49 \%$ \\
\hline Tri-Lingual Journals & Frequency \\
\hline English, Russian, Ukrainian & 5 \\
\hline English, Portuguese, Spanish & 4 \\
\hline English, French, German & 2 \\
\hline English, Czech, Slovak & 1 \\
\hline English, French, Italian & 1 \\
\hline English, French, Portuguese & 1 \\
\hline English, French, Romanian & 1 \\
\hline English, French, Spanish & 1 \\
\hline \multirow[t]{2}{*}{ English, Georgian, Russian } & 1 \\
\hline & Total $=17(2.83 \%$ \\
\hline Quadra-Lingual Journals & Frequency \\
\hline English, French, Portuguese, Spanish & 2 \\
\hline English, French, German, Russian & 2 \\
\hline \multicolumn{2}{|l|}{ Total $=4(0.67 \%)$} \\
\hline Penta-Lingual Journals & Frequency \\
\hline $\begin{array}{l}\text { English, Catalan, Galician, Portuguese, } \\
\text { Spanish }\end{array}$ & 1 \\
\hline \multicolumn{2}{|c|}{ Total $=(528+51+17+4+1)=601$} \\
\hline
\end{tabular}


are published in 22 different languages. Out of the total 601 journals, $528(87.85 \%)$ are monolingual, 52 are bilingual and the rest (21) are multi-lingual. Among 528 monolingual journals, 509 (96\%) are published only in English language. Out of 51 bi-lingual journals, EnglishFrench and English-Spanish combination dominated. Among the multi-lingual journals, French, Spanish, Portuguese, and German predominate besides English. Of which the journal - TEXTOS de la Ciber Sociedad (The TEXTS Ciber Sociedad Magazine (ISSN: 1577-3760) is published in five languages (English, Catalan, Galician, Portuguese, Spanish) simultaneously. Thus, language of mathematics OA journal shows clear domination of European languages with English as the dominant language.

\subsection{Publishers of OA Mathematics Journals}

An attempt was made to find out leading publishers of $\mathrm{OA}$ journals in Mathematics and categorize them. A publisher was considered 'Commercial' if the website clearly indicated a commercial organization like corporation, registered company for profit. Similarly, professional societies, universities and government organizations were respectively identified and categorized. Table 4 shows that as many as 394 publishers are involved in publishing 601 OA journals in Mathematics. Of which, 342 publishers publish only a single OA journal, while 52 publishers publish more than one OA journals. Hindawi Publishing Corporation publishes 55 (9.15\%) journals followed by Academy and Industry Research Collaboration Centre (AIRCC) (24 journals), Springer (13 journals) and Scientific Research Publishing (12 journals). Noteworthy is the fact that along with several not for profit agencies (universities, professional and learned societies) some leading commercial publishers (Springer, De Gruyter Open) are into OA publishing. Therefore, a change of

Table 4. Leading Publishers of OA Mathematics journals

\begin{tabular}{|c|c|c|c|}
\hline \multicolumn{4}{|c|}{ Leading Publishers } \\
\hline Sl. No. & Publisher & Type & Contribution \\
\hline 1 & Hindawi Publishing Corporation & Commercial Publisher & $55(9.15 \%)$ \\
\hline 2 & Academy \& Industry Research Collaboration Centre (AIRCC) & Professional Society & $24(3.99 \%)$ \\
\hline 3 & Springer & Commercial Publisher & $13(2.16 \%)$ \\
\hline 4 & Scientific Research Publishing & Academic Publisher & $12(1.99 \%)$ \\
\hline \multirow[t]{3}{*}{5} & International Association of Comp. Science \& Inf. Tech. (IACSIT) & International Association & \multirow[t]{3}{*}{$8(1.33)$} \\
\hline & Multidisciplinary Digital Publishing Institute (MDPI AG) & Commercial Publisher & \\
\hline & Science \& Engineering Research Support Society (SERSC) & International Association & \\
\hline 6 & Hikari Ltd & Commercial Publisher & $7(1.16 \%)$ \\
\hline \multirow[t]{2}{*}{7} & Computer Science Journals & Individual Journals & \multirow[t]{2}{*}{$6(0.99 \%)$} \\
\hline & MECS Publisher & Commercial Publisher & \\
\hline \multirow[t]{2}{*}{8} & Bonfring & Commercial Publisher & \multirow[t]{2}{*}{$5(0.83 \%)$} \\
\hline & Science Publishing Corporation & Academic Publisher & \\
\hline \multirow[t]{15}{*}{9} & Academy Publisher & Commercial Publisher & \multirow[t]{7}{*}{$4(0.66 \%)$} \\
\hline & American Mathematical Society & Professional Society & \\
\hline & American V-King Scientific Pub. Ltd. (AVSP) & Commercial Publisher & \\
\hline & Hans Publishers & Commercial Publisher & \\
\hline & Institute of Mathematical Statistics & Professional Society & \\
\hline & International Scientific Publication \& Consulting Services (ISPACS) & Commercial Publisher & \\
\hline & VERSITA (Now De Gruyter Open) & Commercial Publisher & \\
\hline & Asian Network for Scientific Information (ANSI net) & Commercial Publisher & \multirow[t]{8}{*}{$3(0.499 \%)$} \\
\hline & Canadian Center of Science and Education (CCSE) & Commercial Publisher & \\
\hline & Institute of Advanced Engineering and Science (IAES) & Professional Society & \\
\hline & Modern Science Publishers & Commercial Publishers & \\
\hline & SCIENPRESS Ltd. & Commercial Publishers & \\
\hline & Society of Digital Information \& Wireless Commun. (SDIWC) & Professional Society & \\
\hline & University of Bologna & Academic Institution & \\
\hline & Vasyl Stefanyk Precarpathian National University & Academic Institution & \\
\hline 11 & Another 25 Publishers having & & 2 each \\
\hline 12 & Another 342 Publishers having & & 1 each \\
\hline \multicolumn{2}{|c|}{ Total 394 Unique Publishers } & & 601 \\
\hline
\end{tabular}


attitude towards OA publishing could be noticed among publishers.

\subsection{Discipline-wise Distribution}

Mathematics finds its application in different branches of science, engineering, medicine, and social sciences. Moreover, due to ever-increasing trends of interdisciplinary research, a large number of journals have emerged which deal with many subjects, one of which may be mathematics, like British Journal of Mathematics and Computer Science; Advances in Mathematical and Computational Methods; American Journal of Computational Mathematics and many more. This paradigm shift might have forced publishers to shift to publishing multidisciplinary journals such as Interdisciplinary Journal of Information, Knowledge, and Management; Human-Centric Computing and Information Sciences; International Journal of Innovative Research in Computer and Communication engineering. Therefore, to categorize these journals under precise subject headings is not feasible. So these journals have been classified under broad subject headings, like computation mathematics, general mathematics, engineering mathematics - which may not be mutually exclusive (Table 5 ).

Table 5. Subject coverage of OA Mathematics journals

\begin{tabular}{lcc}
\hline Subject & $\begin{array}{c}\text { No of } \\
\text { Titles }\end{array}$ & $\%$ \\
\hline $\begin{array}{l}\text { Computational Mathematics (Electronic } \\
\text { computers, Instruments \& Machines) }\end{array}$ & 287 & 47.75 \\
$\begin{array}{l}\text { Mathematics General } \\
\text { Mathematical Statistics (Probability) }\end{array}$ & 229 & 38.10 \\
$\begin{array}{l}\text { Engineering Mathematics ( Engineering } \\
\text { General, Civil \& Industrial ) }\end{array}$ & 17 & 4.16 \\
Mathematical Science - Special Aspects of & 12 & 2.83 \\
$\begin{array}{l}\text { Education } \\
\text { Econometrics ( Economics modelling, }\end{array}$ & 9 & 1.50 \\
$\begin{array}{l}\text { Forecasting, Growth Theory) } \\
\text { Mathematical Physics (General \& Applied }\end{array}$ & 8 & 1.33 \\
$\begin{array}{l}\text { Physics ) } \\
\text { Mathematical Biology (Biological Sciences, }\end{array}$ & 7 & 1.16 \\
$\begin{array}{l}\text { Medicine, Chemistry) } \\
\text { Arts in general (Fine Arts, Visual Arts) }\end{array}$ & 3 & 0.50 \\
$\begin{array}{l}\text { Linguistics \& Philology (Mathematics - } \\
\text { Mass media \& Literature) }\end{array}$ & 2 & 0.33 \\
$\begin{array}{l}\text { Law in general (Comparative \&Uniform } \\
\text { law, Jurisprudence, etc.) }\end{array}$ & 1 & 0.17 \\
$\begin{array}{l}\text { Philosophy (General), Psychology, Religion } \\
\text { Total }\end{array}$ & 1 & 0.17 \\
\hline & $\mathbf{6 0 1}$ & $\mathbf{1 0 0 . 0 0}$ \\
\hline
\end{tabular}

About $48 \%$ of journals are in computational mathematics; followed by general mathematics (38\%) and mathematical statistics (4\%). Rest 10\% titles are from engineering mathematics, educational mathematics, econometrics and mathematical physics. Results indicate that the journals categorized under 'mathematics' in the DOAJ, could also be useful for many other disciplines like computer science, electronics, engineering, media and communication, law, business management, thereby reaffirming the ubiquitous nature of mathematics as discipline.

\subsection{Funding Model of OA Mathematical Journals}

Even for OA journals, publishing is a costly affair. To meet the cost of production, maintenance of servers, publishers of OA journals rely on 'author-pays model' among which Article Processing Charge (APC) is the predominant mechanism frequently used for generating revenue $^{36}$. It is the fee levied on author upon acceptance of article. Generally, amount of APC is journal-specific and negotiable and could be waived totally for some authors ${ }^{37}$.

Table 6 shows variations of publication charges of mathematics OA journals. APC data was not readily available in DOAJ; so it was collected by visiting web sites of individual journals. However, results show that about $20 \%$ of journals in our dataset do not have specific information about publication fee. While majority of journals (67\%) do not charge any fees, about 4\% (23) journals impose some charges (APC/ handling charge/ processing charges, etc.); about $9 \%$ journals impose conditional article processing charges which varies considerably. Finding seems to agree with those of earlier studies $^{38}$ that majority of OA journals do not charge authors for publishing.

Table 6. Publication Fee of OA Mathematics journals

\begin{tabular}{lcc}
\hline Publication Fee & No of Journals & $\%$ \\
\hline Journals charging No APC & 403 & 67.05 \\
Journals with APC & 23 & 3.83 \\
Journals with Conditional & 54 & 8.99 \\
APC & & \\
Information Missing & 121 & 20.13 \\
\hline Total & $\mathbf{7 0}$ & $\mathbf{1 0 0}$ \\
\hline
\end{tabular}

\subsection{Licensing Model of OA Mathematical Journals}

Accessibility and re-usability of Open access content depends on the license under which said document was published. It is found that majority (62\%) of 
journals were devoid of specific licensing information. However, among the used models are different Creative Commons licensing variants, (http://creativecommons. org/), maximum (155) journals have adopted the least restrictive 'Creative Commons License'(CC BY), followed by the most restrictive 'Non Commercial - No Derivative' (CC-BY-NC-ND) attribution (37 journals).

Table 7. Licensing model of OA Mathematics journals

\begin{tabular}{|c|c|c|c|}
\hline Acronym & License Description & Frequency & $\%$ \\
\hline CC BY & $\begin{array}{l}\text { Creative Common } \\
\text { Attribution }\end{array}$ & 155 & 25.79 \\
\hline CC BY-NC & $\begin{array}{l}\text { Attribution-Non } \\
\text { Commercial Uses }\end{array}$ & 21 & 3.49 \\
\hline CC BY-NC-SA & $\begin{array}{l}\text { Attribution-Non } \\
\text { Commercial-Share } \\
\text { Alike }\end{array}$ & 11 & 1.83 \\
\hline CC BY-ND & $\begin{array}{l}\text { Attribution-No } \\
\text { Derivatives }\end{array}$ & 2 & 0.33 \\
\hline $\begin{array}{l}\text { CC BY-NC- } \\
\text { ND }\end{array}$ & $\begin{array}{l}\text { Attribution-Non } \\
\text { Commercial - No } \\
\text { Derivatives }\end{array}$ & 37 & 6.16 \\
\hline CC BY SA & Attribution-Share Alike & 5 & 0.83 \\
\hline \multicolumn{2}{|c|}{ No Licensing Information } & 370 & 61.56 \\
\hline \multicolumn{2}{|c|}{ Total } & 601 & 100 \\
\hline
\end{tabular}

\section{Conclusion}

During the last couple of decades there has been a rapid growth of OA journals across geographical regions and scientific disciplines. Interestingly developing countries such as India, Egypt, and Brazil have been active, which might be a good sign for global OA adoption. Growing involvement of commercial publishers might be a boost for OA movement. Mathematics OA journals are highly multidisciplinary as majority of these journals could be useful for researchers in other disciplines. The study also demonstrates that large majority of OA journals in our study do not charge any fees for publishing. Creative Commons Attribution (CC-BY) is the most commonly used licence model offered by the mathematics $\mathrm{OA}$ journals. It was also found that there are some journals, which are neither truly open access nor ostensibly mathematics journals. Probably, some hybrid and some converted multidisciplinary OA journals might have crept into our study population due to their inclusion in DOAJ. One could argue that inclusion of these journals would dilute the inferences! Therefore, the study justifies DOAJ's decision to be stringent about journal selection policy ${ }^{39-41}$. There are numerous ways to extend and complement the present study as there are unexplored areas like digital preservations issues, coverage in indexing and abstracting databases, citation performances, and concerns over predatory journals, etc.

\section{References}

1. Association of Research Libraries (2004). Framing the issue: open access. Washington, DC: Association of Research Libraries, Office of Scholarly Communication, 2004. Available at: http://www.arl.org/scomm/open_access/framing.html.

2. De Bellis, N. (2009). Bibliometrics and Citation Analysis: from the Science Citation Index to Cybermetrics. Lanham, MD: Scarecrow Press, p. 299.

3. Antelman, K. (2004). Do Open-Access Articles have a Greater Research Impact? College and Research Libraries, 65(5):372-82.

4. Norris, M., Oppenheim, C. and Rowland, F. (2008). The Citation Advantage of Open-Access Articles. Journal of the American Society for Information Science and Technology, 59(12):1963-72.

5. Gross, J. and Ryan, J.C. (2015). Landscapes of Research: Perceptions of Open Access Publishing in the Arts and Humanities, MDPI-Publications. 3:65-88.

6. Suber, P. (2006). Open Access Overview. Available at: http:// www.earlham.edu/ peters/fos/overview.htm.

7. Johnson, R.K. (2004). Open Access: Unlocking the Value of Scientific Research. Paper presented at The New Challenge for Research Libraries: Collection Management and Strategic Access to Digital Resources, Conference sponsored by the University of Oklahoma, March 4-5, 2004. http://www. arl.org/sparc/bm doc/OpenAccess_RKJ_preprint.pdf.

8. Report of the MSRI Workshop, Berkeley, California, February 14-16, 2011. Available at: www.msri.org/attachments/ workshops/587/MSRIfinalreport.pdf.

9. Tiles, M. (1984). Mathematics: the Language of Science? The Monist, 67(1):3-17.

10. Hamzina, A. (2013). Mathematics is the Queen of Science. Available at: enu.kz/repository/repository2012/mathematics.pdf.

11. Peter, E (2011). Mathematics: Indispensable Tool for Successful and Balance Human Existence on this Planet. Pelagia Research Library, 2(5):449-56.

12. Amsaveni, N. et. al. (2013). Free Online Journals of Performing Arts: a Special Reference to Directory of Open Access Journals (DOAJ). Indian Journal of Arts, 2(6):10-15.

13. Bansal, N. (2014). Directory of Open Access Journals, Music: A Bibliometric Study. International Journal of Scientific and Research Publications, 4(1):1-9.

14. Lone, F.A. (2014). Open Access Journals in the Field of Education: An Informative Study. World Digital Libraries, $7(2): 123-32$.

15. Aswathy, S. and Gopikuttan, A. (2013). Open Access Literature Productivity of Physics: A DOAJ Perspective. Library Philosophy and Practice, Paper 971. http://digitalcommons. unl.edu/libphilprac/971.

16. Bansal, S. and Singh, N. (2013). Open Access Journals in 
Animal Sciences: An Analytical Study of DOAJ. International Journal of Information Dissemination and Technology, 3(2):86-88.

17. Goyal, V. et. al. (2014). An Analysis of DOAJ: Contribution in the Field of Physics. International Journal of Information Dissemination and Technology, 4(1):92-94.

18. Kumar, D. (2014). A Bibliometric Analysis of Directory of Open Access Journals: Environmental Science (1972-2013). E-Library Science Research Journal, 2(5):1-12.

19. Lihitkar R.S. et. al. (2013) Open Access Zoology Journals on DOAJ: An Analytical Study. International Journal of Life Sciences, 1(4):321-27.

20. Manikandan, M. and Amsaveni, N. (2014). Open Access of E -Journals in Agriculture and Food Sciences in DOAJ: A Scientometric Study. Journal of Advances in Library Science, 3(1):53-56.

21. Nisha, F. and Ahmad, H. (2014). Analysis of Open Access Scholarly Journals in Chemistry. Library Philosophy and Practice, Paper 1100. http://digitalcommons.unl.edu/libphilprac/1100.

22. Agashe, A.T. et. al. (2010). Free Online Journals on Business Management on Directory of Open Access Journals. SRELS Journals of Information Management, 47(1):41-60.

23. Husain, S. and Nazim, M. (2013). Analysis of OA Scholarly Journals in Media and Communication. DESIDOC Journal of Library and Information Technology, 33(5):405-411.

24. Rath, P.N. (2015). Study of Open Access Publishing in Social Sciences and its Implications for Libraries. DESIDOC Journal of Library and Information Technology, 35(3):177-83.

25. Chauhan, K. (2012). Selected Free E-Journals in LIS in Directory of Open Access Journals. DESIDOC Journal of Library and Information Technology, 32(4):339-46.

26. Kumar, P. (2013). A Bibliometric Study on Open Access Journals in Library Science Discipline in DOAJ. International Journal of Information Library and Society, 2(1):21-29.

27. Mukherjee, B. (2009). Scholarly Research in LIS Open Access Electronic Journals: A Bibliometric Study. Scientometrics, 80(1):169-96.

28. Pujar, S.M. (2014). Open Access Journals in Library and Information Science: A Study. Annals of Library and Information Studies, 61(4):199-202.
29. Rufai, R. et. al. (2011). Open Access Journals in LIS: the Story so far. Trends in Information Management (TRIM), 7(2):218-28.

30. Sivakumaren, K.S. et. al. (2012). A Study on Open Access Journals in LIS: with Reference to DOAJ. International Journal of Library Science, 6(2):80-87.

31. Walters, H.W. and Linvill, C.A. (2011). Characteristics of Open Access Journals in Six Subject Areas. College and Research Libraries, 4. Available at: http://crl.acrl.org/content/72/4/372.full.pdf.

32. Amsaveni, N. et. al. (2013). Open Access of E - Journals in Technology and Engineering to DOAJ: A Scientometric Study. Global Journal for Research Analysis, 2(3):87-89.

33. Choudhury, A. and Khode, S. (2010). Analysis of Open Access Journals in the Area of Computer Science. SRELS Journals of Information Management, 47(3):339-44.

34. Morris, S. (2006). When is a Journal not a Journal? A Closer Look at the DOAJ, Learned Publishing, 19:73-76.

35. Directory of Open Access Journals (2014). What is the Procedure for a Journal being Accepted into DOAJ? Available at: http://doaj.org/faq\#procedure (03/7/2016).

36. Bandi, S. et. al. (2013). Open Access Scholarly Publishing in India: A Scientometric perspective of DOAJ. Available at: http://eprints.rclis.org/21191/.

37. Björk, B. and Solomon, D. (2012). Pricing Principles used by Scholarly Open Access Publishers. Learned Publishing, 25(3):132-37.

38. Drott, M.C. (2006). Open Access. Annual Review of Information Science and Technology, 40:79-109.

39. Shieber, S. (2009). What Percentage of Open Access Journals Charge Publications Fees? The Occasional Pamphlet, Retrieved from: https://blogs.law.harvard.edu/ pamphlet/2009/05/29/what-percentage-of-open-accessjournals-charge-publication-fees/.

40. Accessed on 21/7/2015. http://sparc.arl.org/blog/doaj-introduces-new-standards.

41. DOAJ. Accessed on 11/05/2016. Available at: https://doajournals.wordpress.com/2016/05/09/doaj-to-remove-approximately-3300-journals/. 